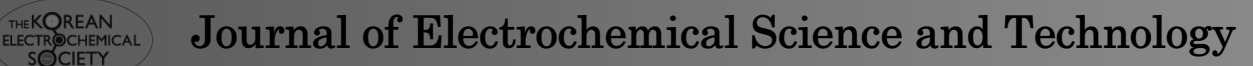

\title{
Formic Acid Oxidation Depending on Rotating Speed of Smooth Pt Disk Electrode
}

\author{
Dongwan Shin ${ }^{1}$, Young-Rae $\mathrm{Kim}^{2}$, Mihwa $\mathrm{Choi}^{3}$, and Choong Kyun Rhee ${ }^{1,2 *}$ \\ ${ }^{1}$ Department of Chemistry, Chungnam National University, Daejeon 305-704, Korea \\ ${ }^{2}$ Gruaduate School of Analytical Science and Technology, Chungnam National University, Daejeon, 305-704, Korea \\ ${ }^{3}$ Future Technology Research Laboratory, Korea Electric Power Corporation (KEPCO) Research Institute, Daejeon 305- \\ 760, Korea
}

\begin{abstract}
This work presents the variation of formic acid oxidation on Pt depending on hydrodynamic condition using a rotating disk electrode. As the rotating speed increases, the oxidation rate of formic acid decreases under voltammetric and chronoamperometric measurements. The coverages of poison formed from formic acid during the chronoamperomertric investigations decrease when the rotating speed increases. As the roughness factor of Pt electrode surface increases, on the other hand, the current density of formic acid oxidation increases. These observations are discussed in terms of the tangential flow along Pt electrode surfaces generated by the rotating disk electrode, which reduces a contact time between formic acid and a Pt site, thus the formic acid adsorption.
\end{abstract}

Keywords: Formic acid, Platinum, Rotating disk electrode, Poison, Roughness factor

Received May 22, 2014 : Accepted June 9, 2014

\section{Introduction}

Formic acid is one of the promising fuels for direct liquid fuel cells [1,2]. Efficient electrocatalysts for formic acid oxidation are Pt and Pt based metals. On Pt surfaces, formic acid is known to be oxidized via dual-path mechanism (Scheme 1) [2]. The pre-requisite is adsorption of formic acid on Pt surfaces, followed by two different oxidation paths. Dehydrogenation path leads directly to $\mathrm{CO}_{2}$ formation, while dehydration path forms poison (similar to $\mathrm{CO}$ ) before completely oxidation to $\mathrm{CO}_{2}$. Because the potentials for poison oxidation is known to be higher than the potential for the dehydrogenation path, removal or inhibition of poison is one of the research directions toward practical Pt electrocatalysts of formic acid oxidation. For example, one way to boost formic acid oxidation on $\mathrm{Pt}$ is the modification of Pt surfaces with $\mathrm{Bi}$, which inhibits poison formation and simultaneously enhances dehydrogenation via ensemble mechanism [3-8].

Rotating disk electrode (RDE) is one of major research tools in fuel cell technology [9]. The main advantage is an enhanced mass transfer of reactants to the electrode surfaces, so that evaluation of catalytic performances is carried out by measuring kinetic currents of electrocatalytic reactions using Koutechy-Levich equation. Furthermore, the hydro-

*Corresponding author. Tel.: +82-42-821-5483

E-mail address: ckrhee@cnu.ac.kr

Open Access DOI: http://dx.doi.org/10.5229/JECST.2014.5.3.82

This is an Open Access article distributed under the terms of the Creative Commons Attribution Non-Commercial License (http://creativ ecommons.org/licenses/by-nc/3.0/) which permits unrestricted non-commercial use, distribution, and reproduction in any medium, provided the original work is properly cited. 


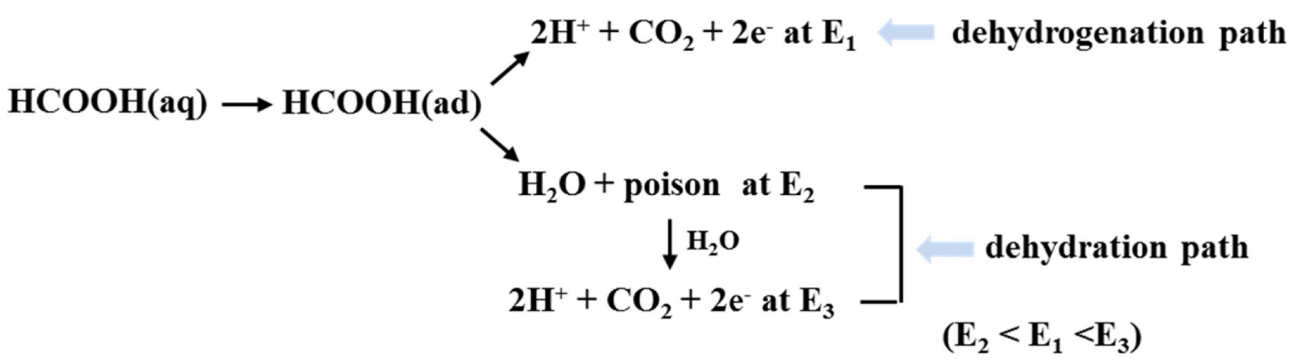

Scheme 1. Dual oxidation paths of formic acid on Pt.

dynamic conditions mimic the flows of electrolytes containing fuels in real fuel cells, so that RDE is an important tool evaluating oxygen reduction reaction in a half-cell configuration. On the other hand, reaction products (including by-products) and reaction efficiency are reachable by employing a ring electrode around a disk electrode to deepen understanding electrocatalytic reactions.

In this work, the effect of hydrodynamic environments generated by RDE on formic acid oxidation on Pt electrode is demonstrated. With rotating Pt electrode during oxidation of formic acid, the oxidation currents under voltammetric and chronoamperometric conditions decreased albeit an enhanced mass transfer of formic acid to the electrode surfaces. Measurements of the amounts of electrocatalytic poison formed from formic acid under various hydrodynamic conditions implies that a fast tangential flow does not allow a contact time long enough for formic acid to initiate its oxidation reaction.

\section{Experimental}

The rotating Pt disk electrode $($ diameter $=5.0 \mathrm{~mm})$ used in this work was purchased from Pine Research Instrument Inc., and the rotating speed was controlled by a rotating electrode speed controller (AFM SRCE, Pine Research Instrument Inc.). Before any experiment, the Pt disk electrode was cleaned by extensive oxidation-reduction cycles in $0.5 \mathrm{M} \mathrm{H}_{2} \mathrm{SO}_{4}$ solution (95 97\%, Merck) in the potential range of $-0.23 \sim 1.23 \mathrm{~V}$ against a $\mathrm{Ag} / \mathrm{AgCl}$ reference electrode with $1.0 \mathrm{M} \mathrm{NaCl}$ solution. The roughness of the Pt electrode was controlled by polishing diamond pastes or abrasive emery papers of proper sizes, and the roughness factors were determined by electrochemically active surface area (estimated using hydrogen underpotential charges) divided by the geometrical surface area.
Electrochemical oxidation of formic acid studies were performed in $2.0 \mathrm{M}$ formic acid ( $98 \%$, Wako) in $0.5 \mathrm{M} \mathrm{H}_{2} \mathrm{SO}_{4}$ solution. Chronoamperometric measurements were carried out as follows: (i) a cyclic voltammogram of formic acid oxidation was recorded in the potential range of $-0.23 \sim 1.23 \mathrm{~V}$ under a proper rotating speed, (ii) the electrode potential was held at $1.23 \mathrm{~V}$ for $10 \mathrm{sec}$ to remove poisons, (iii) the electrode potential was held at $-0.23 \mathrm{~V}$ for $1 \mathrm{sec}$ to reduce the Pt surface oxide, and then (iv) the electrode potential was jumped to a proper one to record chronoamperometric current for $50 \mathrm{~min}$. The amount of poison formed under a chronoamperometric condition was achieved as follows: (i) $0.1 \mathrm{~mL}$ of a $0.1 \mathrm{M}$ solution of KI $(99.99 \%$, Sigma-Aldrich) was injected to the formic acid solution $(\sim 100 \mathrm{~mL})$ during a chronoamperometric measurement with keeping the Pt electrode rotating to blocking the bare Pt sites, (ii) the formic acid solution was replaced with $0.5 \mathrm{M}$ $\mathrm{H}_{2} \mathrm{SO}_{4}$ solution under potential control, and (iii) the poison was stripped off by a voltammetric scan from $-0.23 \mathrm{~V}$ to $1.23 \mathrm{~V}$. The coverage of poison is defined as the charge ratio of poison to underpotential hydrogen divided by 2 .

\section{Results and discussion}

Fig. 1 shows cyclic voltammograms of formic acid oxidation depending on rotating speed of a Pt disk electrode. Fig. 1(a) demonstrates the oxidation behavior of formic acid on Pt when the electrode was not rotated: the oxidation current in the anodic scan is not significant due to poison formation until the oxidative removal of poison reaches to $0.6 \mathrm{~V}$, while the oxidative current in the cathodic scan increases rapidly at $0.55 \mathrm{~V}$ and subsequently decreases as poison accumulates on the electrode surface below $0.4 \mathrm{~V}$. Rotation of the Pt electrode modifies the voltammo- 


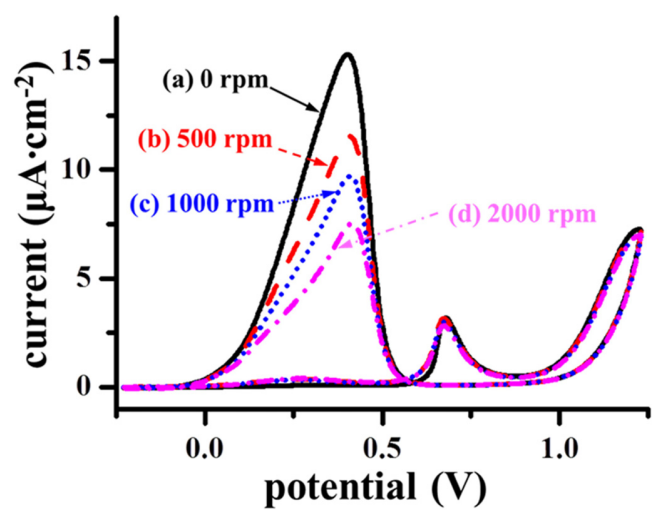

Fig. 1. Cyclic voltammograms of formic acid on a Pt disk electrode in a $0.5 \mathrm{M} \mathrm{H}_{2} \mathrm{SO}_{4}$ solution with $2.0 \mathrm{M}$ formic acid under various rotating speeds: (a) $0 \mathrm{rpm}$, (b) $500 \mathrm{rpm}$, (c) $1000 \mathrm{rpm}$, and (d) $2000 \mathrm{rpm}$. The roughness factor of the Pt electrode was 1.43. Scan rate: $50 \mathrm{mV} / \mathrm{sec}$.

grams of formic acid oxidation (Figs. 1(b)-(d)). Specifically, the voltammograms observed during anodic scan rarely depend on rotating speed. However, the oxidation currents recorded during cathodic scan decrease as the rotating speed increases, although the voltammetric shapes and peak potentials remain unchanged. These observations imply that rotating the Pt electrode hampers the oxidation process of formic acid without modification of reaction routes.

Fig. 2(a) illustrates the dependence of chronoamperograms recorded at $0.22 \mathrm{~V}$ on rotating speed. It is clear that the faster the rotating speed, the lower the oxidation current under the chronoamperometric condition. Fig. 2(b) displays the plots of chronoamperometric current against oxidation potential under various rotating speeds. Regardless of rotating speed, the onset potential of formic acid oxidation is around $0.1 \mathrm{~V}$, and the maximum current is recognizable in the potential range of $0.270-0.40 \mathrm{~V}$. However, the maximum current decreases as the rotating speed increases, confirming again that rotating the Pt disk electrode reduces the formic acid oxidation rate.

Rotation of an electrode enhances two physical mass transfer processes on the electrode surface [10]. The forced flow of solution in the perpendicular direction to the electrode surface narrows the stagnant diffusion layer, so that the mass transfer of reactants to the electrode is enhanced. The other forced flow in the tangential direction sweeps the electrode surface, so that products (or byproducts) as well as unreacted reactant are removed in the vicinity of the
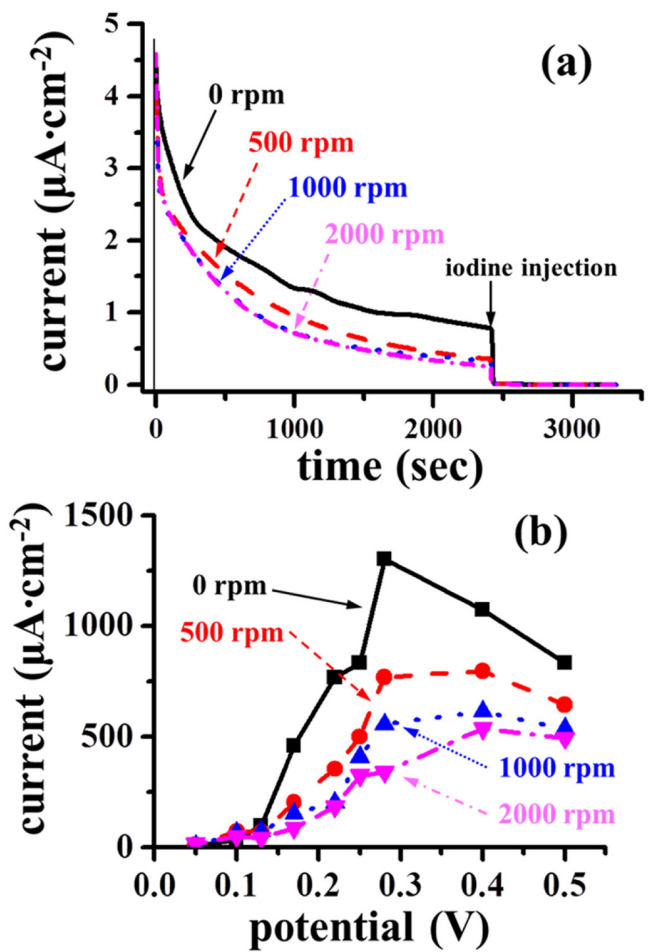

Fig. 2. Chronoamperometric measurements of formic acid oxidation on a Pt disk electrode in a $0.5 \mathrm{M} \mathrm{H}_{2} \mathrm{SO}_{4}$ solution with $2.0 \mathrm{M}$ formic acid under various rotating speeds. (a) Chronoamperograms observed at $0.22 \mathrm{~V}$ under various hydrodynamic conditions. (b) Variations of chronoamperometric currents observed at $2400 \mathrm{sec}$ after potential jump as a function of potential. An iodine solution was injected to halt the formic acid oxidation (See the text for details). The roughness factor of the Pt electrode was 1.43.

electrode surface quickly. Concerning the above observations, two hypotheses may account for the adverse effect of rotation on formic acid oxidation: one is that an enhanced mass transfer of formic acid toward the electrode surface may build up more poison via dehydration path to reduce bare $\mathrm{Pt}$ areas for dehydrogenation path, while the other is that a fast tangential flow on the surface may not allow a sufficient time for formic acid to contact with the surface to initiate the oxidation routes. A clue to determine the operating one out of the two hypotheses is the amount of poison from formic acid depending on rotating speed. If the former hypothesis is operational, the amount of poison would increase under rotating conditions. On the other hand, a decrease in the amount of poison on rotating Pt disk electrode is anticipated in the case of the latter hypothesis. 
Fig. 3 shows stripping voltammograms of poison produced on rotating Pt electrodes at $0.13 \mathrm{~V}$ under a chronoamperometric condition. Specifically, an iodine solution $(\sim 0.1 \mathrm{~mL})$ of $0.1 \mathrm{M}$ was injected into a formic acid solution $(\sim 100 \mathrm{~mL})$ at $2400 \mathrm{sec}$ after a potential jump from $-0.23 \mathrm{~V}$ to $0.13 \mathrm{~V}$. The injected iodide adsorbs bare Pt sites without replacing the already existing poison to prevent further adsorption of formic acid $[11,12]$, so that the oxidation of formic acid was completely prevented as exemplified by the sudden current drop at $2400 \mathrm{sec}$ in Fig. 2(a). The intention of adsorbed iodine protection is to inhibit further formation of poison from formic acid under an uncontrolled situation possibly occurring during a replacement of the formic acidcontaining solution with a formic acid-free $\mathrm{H}_{2} \mathrm{SO}_{4}$ solution for poison stripping. In Fig. 3(a), the poison is oxidized around $0.6 \mathrm{~V}$, and the oxidative removal of the
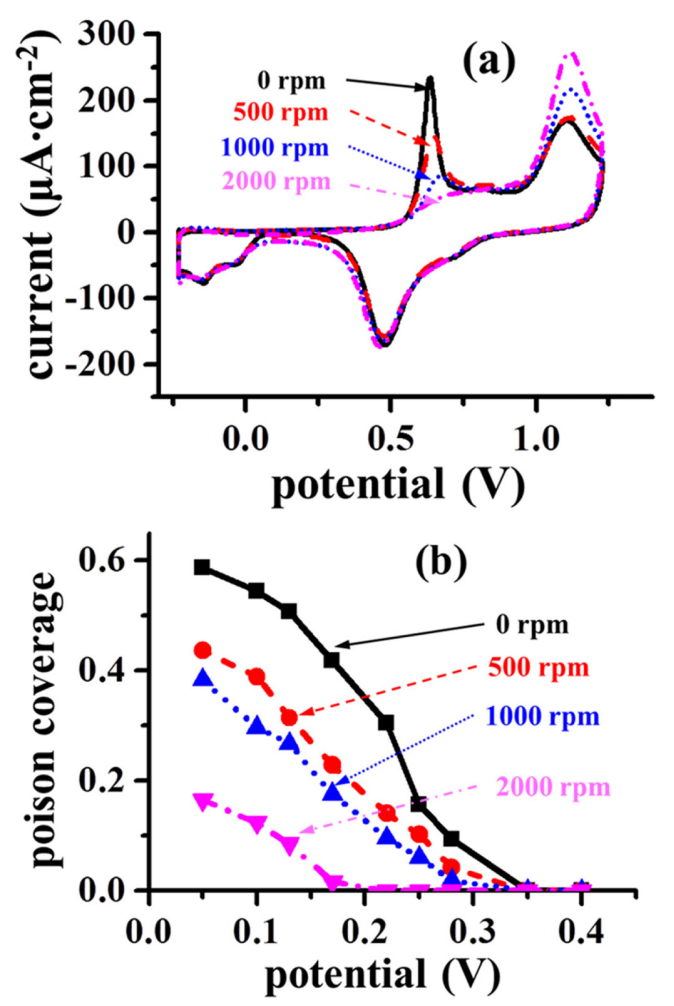

Fig. 3. (a) Stripping voltammograms of poison formed from formic acid on a Pt disk electrode in a $0.5 \mathrm{M} \mathrm{H}_{2} \mathrm{SO}_{4}$ solution with $2.0 \mathrm{M} \mathrm{HCOOH}$ during chronoamperometric potential hold at $0.13 \mathrm{~V}$ for $2400 \mathrm{sec}$ under various rotating speeds. The poison stripping was carried out in in a $0.5 \mathrm{M} \mathrm{H}_{2} \mathrm{SO}_{4}$ solution without formic acid. (b) Variations of poison coverage as a function of potential under various rotating speeds. The roughness factor of the Pt electrode was 1.43. adsorbed iodine take place at the potential higher than $1 \mathrm{~V}$. As the rotating speed increases, the charge of poison stripping certainly decreases while the oxidation charge of the adsorbed iodine increases. It is remarkable that when the rotating speed is $2000 \mathrm{rpm}$, poison was rarely detected. Fig. 3(b) shows plots of poison coverage against formic acid oxidation potential under the investigated rotation conditions. Clearly, the rotation of Pt electrode reduces the amount of poison formed from formic acid, revealing that formic acid swept by the fast tangential flow does not have enough time to adsorb on the surface, thus to form poison. Combining Figs. 3(a) and (b) indicates that although rotating Pt electrode leads to less poison (equivalently more bare $\mathrm{Pt}$ ), the oxidation current via the dehydrogenation route in the potential region around $0.3 \mathrm{~V}$ becomes smaller as the rotating speed increases. This specific observation also support that the dehydrogenation route is limited by the amount of adsorbed formic acid.

Fig. 4(a) shows the cyclic voltammograms of formic acid on Pt electrodes of different roughnesses
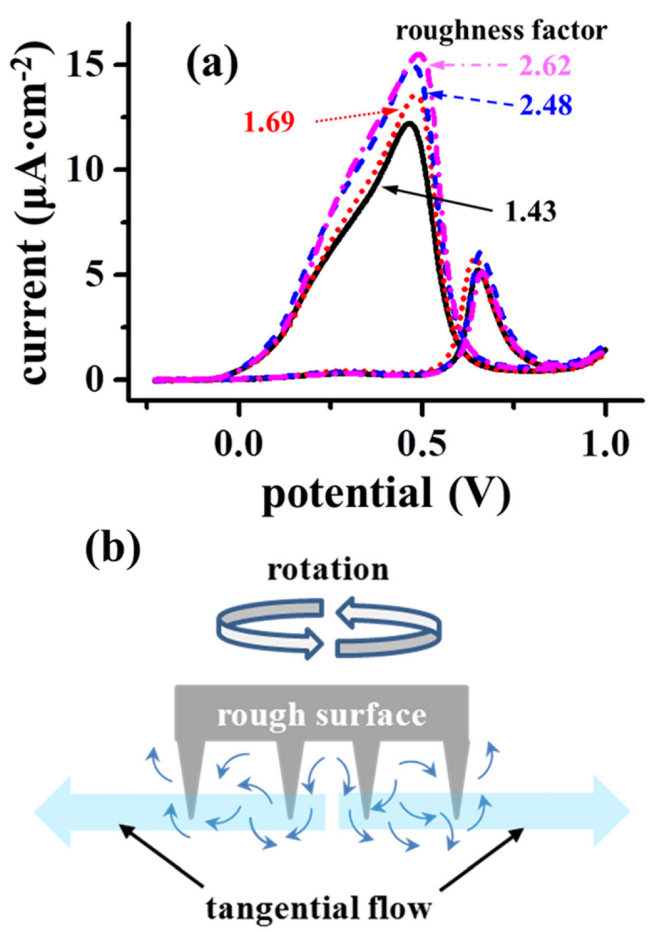

Fig. 4. (a) Dependence of cyclic voltammograms of formic acid on $\mathrm{Pt}$ disk electrodes of various roughness factors in a $0.5 \mathrm{M} \mathrm{H}_{2} \mathrm{SO}_{4}$ solution with $2.0 \mathrm{M}$ formic acid under a rotating speed of $500 \mathrm{rpm}$. (b) Schematic presentation of a fast tangential flow on a rough surface. 
under a rotating speed of $500 \mathrm{rpm}$. As the roughness factor of Pt electrode increases from 1.43 to 2.62, the oxidation current density increases clearly. As the Pt electrode surface becomes rougher, the tangential flow would slow down due to a resistance against sweeping flow as illustrated in Fig. 4(b). Accordingly, formic acid would have a sufficient time to adsorb on a rough $\mathrm{Pt}$ surface, which is supported by an increase in chronoamperometric along with the roughness factor (not shown here). Therefore, it is conclusive that the tangential flow is responsible for the decrease in formic acid oxidation on Pt electrodes under hydrodynamic conditions.

A special attention should be paid in evaluation of Pt electrodes towards formic acid oxidation under hydrodynamic conditions. The presented results in this work reveal that a hydrodynamic condition certainly reduces the formic acid oxidation rate on $\mathrm{Pt}$, depending on the flow rate in the direction tangential to the surface. The experimental parameters determining the tangential flow rate are rotating speed of Pt disk electrode and its surface roughness. Thus, the two experimental parameters should be specified for the comparison of the formic acid oxidation results obtained using Pt disk electrodes under hydrodynamic conditions.

\section{Conclusions}

This work demonstrates that formic acid oxidation on Pt disk electrode was hampered by hydrodynamic condition. Rotating a Pt disk electrode decreased the formic acid oxidation current measured voltammetric and chronoamperometric conditions. Measurements of poison coverage under the various hydrodynamic conditions revealed that the tangential flow along the Pt electrode surface reduced a contact time between formic acid and a Pt site, thus the formic acid adsorption. Also, roughness factor is an important experi- mental parameter to determine the tangential flow rate. Therefore, rotating speed and electrode surface roughness factor should be seriously considered in evaluation of formic acid oxidation on Pt disk electrodes.

\section{Acknowledgement}

This research was supported by the National Research Foundation of Korea (NRF) grant funded by the Korea government (MEST) (NRF-2013R1A1A2007139).

\section{References}

[1] R. Parsons and T. Vandernoot, J. Electroanal. Chem., 257, 9 (1988).

[2] J. M. Feliu, E. Herrero, in Handbook of Fuel CellsFundamentals Technology and Applications, W. Vielstich, A. Lamm, H.A. Gasteiger (Eds.), Vol. 2, John Wiley \& Sons Ltd., New York (2003), Ch. 42.

[3] E. Herrero, A. Fernandez-Vega, J. M. Feliu and A. Aldaz, J. Electroanal. Chem., 350, 73 (1993).

[4] J. Clavilier, A. Fernandez-Vega, J. M. Feliu and A. Aldaz, J. Electroanal. Chem., 258, 89 (1989).

[5] J. Clavilier, A. Fernandez-Vega, J. M. Feliu and A. Aldaz, J. Electroanal. Chem., 261, 113 (1989).

[6] B.-J. Kim, K. Kwon, C. K. Rhee, J. Han and T.-H. Lim, Electrochim. Acta, 53, 7744 (2008).

[7] C. Jung, T. Zhang, B-J. Kim, J. Kim, C. K. Rhee and T.H. Lim, Bull. Kor. Chem. Soc., 31, 1543 (2010).

[8] J. Kim and C.K. Rhee, Electrochem. Comm., 12, 1731 (2010).

[9] T.J. Schmidt and H.A. Gasteiger, in Handbook of Fuel Cells-Fundamentals Technology and Applications, W. Vielstich, A. Lamm, H. A. Gasteiger (Eds.), Vol. 2, John Wiley \& Sons Ltd., New York (2003), Ch. 22.

[10] A.J. Bard and L.R. Faulkner, Electrochemical Methods: Fundamentals and Applications ( $2^{\text {nd }}$ Ed.), John Wiley \& Sons, Inc., New York (2001), Ch. 9.

[11] D. Zurawski, L. Rice, M. Hourani and A. Wieckowski, J. Electroanal. Chem., 230, 221(1987).

[12] M. Wasberg, L Palaikis, S. Wallen, M. Kamrath and A. Wieckowski, J. Electroanal. Chem., 256, 51 (1988). 